\title{
An Instructive Flow Chart for Optimising the Electrical Cable Sizing Design Procedure
}

\author{
Emad Al-Mahdawi
}

\begin{abstract}
In this paper, the analysis is focused on the methodology of installation design and cable sizing assessment. Cable overheating leads to melting of the insulation, resulting in exposed conductors and short circuits or electric shock, and possibly fire. Therefore, reliable power network, supply and operation have gained an increasing importance for the modern world. Cabling in a system is the means by which the source of energy is distributed to load. The size of the cable is directly proportion to the size of the load. Selecting a small size cable for a load could lead to overload and a catastrophic failure. Hence the correct selection procedure for the cable is of critical importance for both functionality and safety.

This paper is addressed to electrical installation design engineers, learners and programmers with an interest in the optimisation of the cabling design by following the Instructive Cable Sizing Flow Chart (ICSFC). The proposed ICSFC, attached in Appendix $A$ in this article, is considered a phase-gate technique planned and designed to get better results with less effort. Due to the fact that every installation is different, this paper aims to show the major principles and decisions involved in cable sizing as well as giving a prescriptive step-by-step flow chart to do the job precisely.
\end{abstract}

Keywords: Cable sizing, Diversity, Maximum demand, Safety supply, Earthing

\section{INTRODUCTION}

The development of wiring regulations has progressed with the 1st wiring regulations, presented in 1882, containing of only 4 pages and comprising 21 regulations. The objective of the wiring regulations is to set out the rules for the design and erection of electrical installations so as to provide safety and proper functioning for the intended use. The international standards, e.g., British Standards (BS), National Electrical Code (NEC), International Electrotechnical Commission (IEC) and Institute of Electrical and Electronic Engineering (IEEE), use the same underpinning theorems for any cable sizing calculation. The Wiring Regulations (BS7671) are intended to be applied to the design, erection and verification of electrical installations generally. However, BS7671 is a non-statutory document therefore it is not an act of law [20]. It is referenced by a number of statutory documents. Therefore, it can be considered an expansion of the Electricity at Work Regulation (EAWR) 1989 [6]. The BS7671 has been extensively referred to the Health and Safety at Work (HSE) Guidance as compliance is deemed to achieve conformity with the EAWR1989 [6, 21, and 7].

Revised Manuscript Received on April 02, 2020.

* Correspondence Author

Dr.Emad Al-Mahdawi*, Department of Electrical Engineering, Midkent College, Kent - United Kingdom emadalmahdawi@yahoo.com

(C) The Authors. Published by Blue Eyes Intelligence Engineering and Sciences Publication (BEIESP). This is an open access article under the CC BY-NC-ND license (http://creativecommons.org/licenses/by-nc-nd/4.0/)

\section{PRE-DESIGN PROCEDURE}

There are some important steps to be carried out before starting the design of an Electrical installation. These are:

\section{Purpose of the Installation}

The use or purpose of the building or installation can be classified into three broad groups:

Industrial Installation: This will have a large proportion of electrical machinery - probably three-phase. The characteristics of this installation are large transient (starting) loads, possibly poor power factors, no air conditioning, small lighting load and no high integrity supplies.

Commercial installation: This may well have a large amount of IT equipment of single-phase. The expected characteristics are high integrity supplies, possible a UPS, pulsed loads - flicker \& harmonics, essential and nonessential loads, air conditioning, lifts and high lighting load.

Residential installation: This system implies heavy loads, single-phase loads, medium lighting load, possible lifts, possible air conditioning, no high integrity supplies and distributed pattern of loads.

\section{Maximum Demand (MD)}

The purpose of an installation remarkably affects the supply required by it. However, it is compulsory to estimate the Maximum Demand in Ampere that will be required from the supplier. This supports determine the category of supply voltage (LV or HV). BS7671 provides useful guidance for estimating MD and applying diversity [21, 22]. Diversity Factor (DF) is defined as the percentage of the algebraic accumulation of the single connected maximum loads of different sub-circuits to the MD of the whole system.

The concept of the DF is being utilised to decrease the cost of power generation [3]. The Load Factor (LF) is welldefined as the proportion of the mean load over a designated period of time to the peak load occurring in that period [21]. The LF should be estimated at the design stage.

It is important to outline that a high load factor close to unity provides better power usage [9]. The MD can be reduced by adjusting the load factor to nearer unity. The final value for MD must also make an allowance for power factor. It must be noted that the MD increases with a poor power factor. Therefore, applying a correction for the power factor, the MD becomes close to unity.

Table1: Diversity Factor according to circuit function [8]

\begin{tabular}{l|l|}
\hline Circuit Function & Diversity Factor \\
\hline Lighting & 0.9 \\
\hline Heating and Air conditioning & 0.8 \\
\hline Socket-outlets & 0.7 \\
\hline Powerful Motor & 1 \\
\hline
\end{tabular}




\begin{tabular}{|l|l|}
\hline For second powerful motor & 0.8 \\
\hline For all other motors & 0.6 \\
\hline Receptacle Outlets & 0.1 \\
\hline Air compressor & 0.5 \\
\hline
\end{tabular}

\section{Final Circuit Diversity}

Reference [20] shows adequate diversity guidance that should be used for all standard circuits whenever applicable. It is always recommended to check the assumptions made. A final circuit that has two $2.5 \mathrm{~kW}$ drives attached where it is unlikely that both will operate all at once does not need to be sized at 5kW. The installation design is based on current drawn so always consider power factor at every step. Final circuits, such as ring mains, radials etc. are already diversified, no additional diversity should be added to these "pre designed" circuits [9, 21].

\section{a. Board Diversity}

Diversity factors for groups of circuits which may be connected to the same board are given in [9]. Sizing the incoming or sub-main cable should be accomplished on diversified loads in a similar manner to the considerations given to final circuits. For example, if a distribution board feeds a set of heating pumps and a set of chilled water pumps, it is unlikely that both sets will be operating at the same time. The sub-main for this could be sized to meet the maximum demand of the largest set [13, 22].

Table 2: Diversity Factor for distribution switchboards

[8]

\begin{tabular}{|l|c|}
\hline \multicolumn{1}{|c|}{ Number of circuits } & Diversity Factor \\
\hline Assemblies entirely tested 2 and 3 & 0.9 \\
\hline 4 and 5 & 0.8 \\
\hline 6 to 9 & 0.7 \\
\hline 10 and more & 0.6 \\
\hline $\begin{array}{l}\text { Assemblies partially tested in every case } \\
\text { choose }\end{array}$ & 1 \\
\hline
\end{tabular}

Table 3: Diversity Factor for an apartment block [9]

\begin{tabular}{|l|c|}
\hline Apartment & Diversity Factor \\
\hline 2 To 4 & 1 \\
\hline 5To 19 & 0.78 \\
\hline 10To 14 & 0.63 \\
\hline 15To 19 & 0.53 \\
\hline 20To 24 & 0.49 \\
\hline 25To 29 & 0.46 \\
\hline 30 To 34 & 0.44 \\
\hline 35 To 39 & 0.42 \\
\hline 40To 40 & 0.41 \\
\hline 50 To Above & 0.40 \\
\hline
\end{tabular}

The instantaneous operation of entirely connected loads has always some grade of diversity and this element is allowing for assessing purposes by means of a Diversity Factor.

The Diversity factor (DF) is applied to each assembly of electrical loads irrespective. The estimation of these factors is the responsibility of the design engineer.

\section{b. Complex Installations}

Complex installations are analysed according to type and purpose. The current method is purely an estimation experience and familiarity will rule [21].

$\mathrm{P}_{\max }=g \mathrm{P}_{\mathrm{i}}$

$\mathrm{P}_{\max }=$ Maximum demand (sum of all loads)

$\mathrm{P}_{\mathrm{i}}=$ Total installed load

$\mathrm{g}=$ the installation demand factor, typically $\mathrm{g} \leq 1$

Demand factor is often used in association with points of utilisation per current using equipment. The method is as before, where $\mathrm{g}$ is dependent on the number of dwellings [9, 21].

\section{Coincide Factor}

The coincidence factor (CF) is the reciprocal of the diversity factor and has the same metric scalar.

The coincidence factor $=$ MD of a load / sum of the individual MDs of complete system [12].

$$
C F_{n}=\frac{1}{D F^{n}}=\frac{\sum_{i=1}^{n} D_{i(\max )}^{n}}{D_{c(\max )}^{n}}
$$

Where $\mathrm{n}$ is the number of connected loads, e.g. households, Di (max) is the individual maximum demand of a single load $i$ and DC (max) is the maximum coincident demand of $r$ loads.

This shows three inversed values of CF based on three values of DF: minimum, maximum and expected. It is understandable that the sum of the individual maximum demand is always larger or equal to the maximum demand of the whole system. Therefore, the estimated coincidence factor always changes between 0 and 1 . Commonly, a reduced value of $\mathrm{CF}$ can be achieved by increasing the number of connected systems.

The importance of the DF and CF is that not all loads usually reach to the peak at the same time. Thus, for the sake of the economic sizing of the power plant, the coincidental and non-coincidental maximum load demands are important for design engineers [3, 12 and 4].

\section{Number and type of live conductors}

Once the MD has been established, the DNO (Distribution Network Operator) might offer the supply in either: HV usually $11 \mathrm{kV}$ (TP) or LV-400 V (TPN) [19].

The threshold is typically between 250 and $500 \mathrm{kVA}$ (based on $400 \mathrm{~V}$ ). For a single structure, the DNO will typically be in charge for all connections to the consumer terminals. On larger sites or buildings, the DNO would probably require an intake substation from the consumer. This would make metering simpler and aid in the diversity calculations. However, this would be more expensive. As soon as the supply voltage has been determined, the type of earthing arrangement must be decided, e.g. TN-C, TN-S, TN-C-S, TT or IT [9, 19 and 21].

This will undoubtedly be introduced by the DNO taking into consideration the energy source and the local earthing facilities. The reason of the system earth is to curb the potential of the live conductor with respect to earth to values which the insulation is designed [16, 19]. Earthing equipment is concerned with protection of life and property, and is designed to prevent the occurrence of potential dangers on parts of the system not normally live.

The diverse approaches of system earthing are:

Published By:
Blue Eyes Intelligence Engineering

$\&$ Sciences Publication

(C) Copyright: All rights reserved. 
1. TT System (Direct Earthing). The consumer's protective conductor (CPC) is linked to the earth by an effective earth electrode.

2. TN-C System (Neutralising). A system whereby the consumer's installation comprises earthed concentric wiring or a system of PEN conductors and the external or PEN conductors are bonded to the earthed neutral of the supply [20].

3. TN-S System (Direct Earthing to a continuous earth wire). The neutral and earthing conductor of the source are linked together close to the source, and the customer's main earthing terminal is linked to a metallic earth return path.

4. TN-C-S System (Protective Multiple Earthing). The supply arrangement is normally $\mathrm{TN}-\mathrm{C}$ and the installation arrangement TN-S. The more common name for this type of supply arrangement is Protective Multiple Earthing (PME) [16, 20]. The PEN conductor is also referred to (CNE) conductor. The PEN conductor is usually earthed at several points. However, an earth electrode may be required at or near a consumer's installation.

5. IT System (Impedance or Resistance Earthing). The source is either connected to earth through a current limiting impedance or is isolated from earth. As the source of the supply voltage is not directly earthed, this system is not allowed inside the UK. However, all visible conductive parts are linked to an earth electrode [16, 21].

\section{Supplies for safety and standby purposes}

The competence of supplying an appropriate plan, installation, management and operation of power systems is necessary for the consistent of reliability and survivability for the whole network $[4,15]$. An unexpected loss of power will disrupt most businesses and it could lead to a total failure to trade. As a frequent of an instantaneous of mains power failures, some businesses have gone into insolvency or liquidation. However, it is not only total mains failure or "black-outs" which can trigger devastating impacts. Numerous electrical components, for example, computer networks, are liable to power sags, brown-outs, power surges, noise and radio frequency interference (RFI), and supply frequency changes $[10,11]$.

Such loads are often referred to as "critical loads", partly because their continuous operation is essential to the running of the designed business, and because they necessitate additional reliable power supply in order to guarantee their function. Consequently, an uninterruptible power supply system should be considered. This system is installed between supply and loads, initially provided for short-term duty using flywheels. It provides power during loss of mains power whilst a standby generator runs, or while normal supply is re-instated [11]. Examples of these systems are:

- $\quad$ Static -Energy storage (batteries).

- Rotary - Diesel generator.

\section{DESIGN PROCEDURE - CABLE SIZING:}

Ever since the early days of electrical distribution, it has been apparent that, without devices for automatically disconnecting from the supply, cables can be damaged by overcurrent. This frequently fallouts in fires, causing destruction to property and loss of life. The accurate cable estimation and the effectual proposal of a circuit protection scheme are therefore vital to the safety of all installations. According to the newly constructive ICSFC the common methodology of cable sizing can be summarized as follows: Step one: The most convenient way to establish a rating for a specific cable design is to calculate a current which can be carried steadily (often called a sustained rating) under prescribed standard conditions.

Determination of the load current Ib :

$\mathrm{I}_{\mathrm{b}}=\mathrm{P} / \mathrm{VL} \times \cos (\Phi)$;

Step two: Choose an appropriate protective device and maximum earth loop fault Zsmax, the main reason for a protective device is to protect the installation from damage. According to section 433 [20], the operating characteristics of a device protecting conductor against overload are obligatory to content the three conditions:

1. The nominal current or current setting of the protective device (In) should be higher than the load current $\left(\mathrm{I}_{\mathrm{b}}\right)$ of the circuit.

2. The nominal current of the protective device (In) should not be higher than the lowest of the currentcarrying capacities $\left(\mathrm{I}_{\mathrm{z}}\right)$ of the conductor of that circuit.

3. The current $\left(I_{2}\right)$ causing actual operation of the protective element should not be less than 1.45 times the lowest $\left(\mathrm{I}_{\mathrm{z}}\right)$ of the conductor of that circuit [12].

Protective devices like BS 88-2, BS 88-3, a Circuit Breaker BS EN 60947-2, and BS EN 61009-1 can be chosen from tables 41.2, 41.3 and 41.4 [21]. These tables also provide the value of maximum earth fault loop impedance $\left(Z_{\text {smax }}\right)$. Therefore, automatic disconnection of supply (ADS) is the extensively used method to protect against electric shock in an installation. It achieves the protection by managing the size and duration of voltages between exposed-conductive parts and Earth.

The main difference between these tables is the Maximum Disconnection Times (MDT). Based on table 41.1 [21], the MDT table is applied to final circuits with a limited rated current between 63A with one or more circuit outlet or $32 \mathrm{~A}$ for a fixed connected device. The time for TN circuits varies between 0.4 seconds for 230 AC voltage to $0.2 \mathrm{~s}$ for 400 volt. However, these values become $0.2 \mathrm{~s}$ to $0.07 \mathrm{~s}$ for TT circuits for the same mentioned voltages. It should be also noted that for a distribution circuit the MDT is $5 \mathrm{~s}$ for TN circuit and $1 \mathrm{~s}$ for TT circuit [21].

Step three: Estimate Tabulated Current (It), appropriate factors may then be applied to cater for the actual installation conditions and mode of operation to determine the tabulated current (It). However, the installation condition factors explain whether the installed cable will be over or underground,

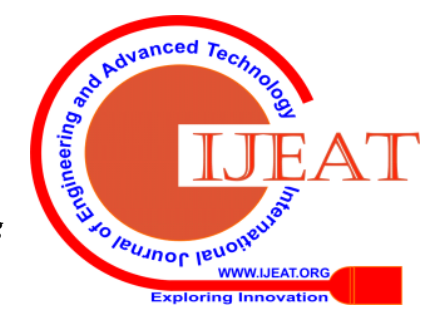


ambient and soil temperature, cable spacing, depth of buried, trefoil or laid left, or cable bunching [9, 21 and 22]. After arriving at the conclusion, the cable`s tabulated current should be calculated based on the construction and installation factors [21].

$I_{t} \geq \frac{I_{n}}{\left(C_{a} \times C_{i} \times C_{g} \times C_{f} \times C_{s} \times C_{c} \times C_{h} \times C_{d}\right)}$

Where the rating factors are:

$\mathrm{C}_{\mathrm{a}}$-Ambient temperature from 20 0C nominal, Tables 4B14B2

$\mathrm{C}_{\mathrm{i}}$ - Thermal Insulation-cables are in thermally insulated wall or ceiling, Table 52.2

$\mathrm{C}_{\mathrm{g}}$ - Grouping with other cables, Tables 4C1 - 4C5

$\mathrm{C}_{\mathrm{f}}-0.725$ if the protection device is a fuse to BS 3036, otherwise 1

$\mathrm{C}_{\mathrm{C}}$ - Buried in ground or conduit system, Table 3B3

$\mathrm{C}_{\mathrm{S}}$ - Thermal resistivity of soil, Tables 4C1 - 4C5

$\mathrm{C}_{\mathrm{h}}$ - Harmonic content for triple harmonic currents in 4 and 5 core cables, Table $4 \mathrm{Aa}$

$\mathrm{C}_{\mathrm{d}}$ - Depth of buried cables, Tables 4B4

The following formulae is applied for groups of cables [14]:

$I t \geq \frac{1}{\left(C_{a} \times C_{i} \times C_{s} \times C_{c} \times C_{d}\right)} \sqrt{\left(\frac{I_{n}}{C_{f} C_{c}}\right)^{2}+0.48 I_{b}^{2}\left(\frac{1-C_{g}^{2}}{C_{g}^{2}}\right)}$

The air temperature and permissible temperature growth are considered the crucial elements in establishing ratings for typical operating conditions for specific installations. Throughout operation, cables withstand electrical losses which perform as heat in the conductor, insulation and metallic components. The cable`s current rating is reliant on the method this heat is dissipated to the surroundings. The insulation material, without undue ageing, for a reasonable maximum life can be estimated as the cable`s maximum temperature is fixed. Then by choosing a base ambient temperature for the surroundings, a permissible temperature increase is obtainable from which a maximum cable rating can be estimated for a particular condition [14, 8].

Under steady conditions, the deviation between the cable temperature and the external ground is associated to the amount of total heat losses and the regulation of heat flow. Heat transfer associates to current, temperature variance and the thermal resistance in the cable and surroundings. From this basis, the heat losses are often referred to as ohmic losses and using this analogy it is feasible to concept a circuit diagram as illustrated in Figure 1.

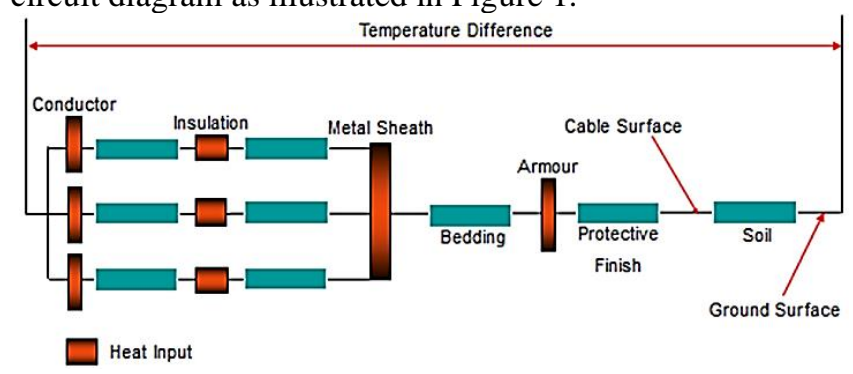

Figure 1: A Modelling diagram of heat generated in a 3 core metal sheathed cable.

Figure 1 demonstrates how the input heat at several positions has to transfer through a number of layers of different thermal resistance. The flowing of heat within a cable is practically radial but externally it is not so and allowance must be made for the method of installation. Figure 2, which illustrates the pattern of heat dissipation for three single-core cables. The picture illustrates the importance of making allowance for the depth of burial cables. It could also be expanded to illustrate the effects of nearby cables in close proximity $[9,20]$.

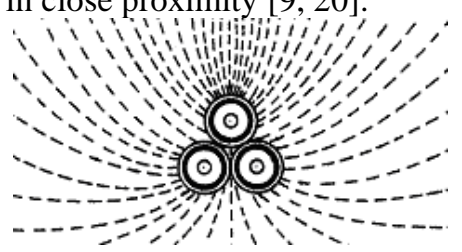

Figure 2: Heat Flow from a Circuit of Single-Core Cables installed in Trefoil.

Step four: With the help of method of installation, operating temperature, cable bunching and spacing, and type of cable, determining the current carrying capacity and crosssectional area of the cable can be done from tables 4D1A 4J4A [21]. Table 4 shown below can be used for choosing the appropriate Installation and Reference Methods. This table was derived from Appendix 4 [21].

Table 4: Installation and Reference Methods.

\begin{tabular}{|c|c|c|l|}
\hline Reference Method & Subdivision & Conductor`s type & \multicolumn{1}{|c|}{ Installation } \\
\hline \multirow{2}{*}{ A } & A1 & Single Core & In conduit in a thermally insulated wall \\
\cline { 2 - 4 } & A2 & Multicore Cable & In a thermally insulated wall \\
\hline \multirow{2}{*}{ B } & B1 & Single Core & In conduit, trunking, duct on a wall \\
\cline { 2 - 4 } & B2 & Multicore Cable & In conduit, trunking, duct on a wall \\
\hline C & C & Multi or Single Core & $\begin{array}{l}\text { On a wooden wall or fixed directly to walls or } \\
\text { ceilings or unperforated trays }\end{array}$ \\
\hline D & D1 & Multi or Single Core & In conduit buried in the ground \\
\cline { 2 - 4 } & D2 & Multi or Single core & buried directly to the ground \\
\hline E & E & Multicore cable & In free air \\
\hline
\end{tabular}

Published By:

Blue Eyes Intelligence Engineering

\& Sciences Publication

(c) Copyright: All rights reserved. 


\begin{tabular}{|c|c|c|l|}
\hline G & G & Single core cables & $\begin{array}{l}\text { Laid flat and spaced in free air (Horizontal or } \\
\text { Vertical) }\end{array}$ \\
\hline
\end{tabular}

Step five: Check the voltage drop. The aim of this examination to confirm that the voltage provided to the load is within its design limits. The maximum permissible voltage drops measured from the origin to the point of calculation for three phase and single-phase supply voltage are $+10 \%,-6 \%$ respectively $[21,22]$. The length $(L)$ of the conductor has an influence on the cable selection and voltage drop. Excessive voltage drop, lower than the permissible voltage level, causes the appliance to draw more current to meet its rated power. This could cause a massive growth in heat generated inside the cable:

Heat Generated $=I^{2} \times R \times t$

Therefore, the lower the voltage supply to the load, the more heat generated. This may damage the wiring, insulation and might lead to a catastrophic fire [8]. Consequently, the voltage drop must compliant with the wiring regulations. The voltage drop of the cable per ampere per meter can be found in tables 4D1b - 4J4B [5].

$V_{d}=\frac{\left(\frac{m v}{\frac{A}{m}}\right) \times I_{b} \times L}{1000} \quad$ This equation is applied for conductors with CSA $16 \mathrm{~mm}^{2}$ or smaller.

It should be noted that for conductors having a CSA $25 \mathrm{~mm} 2$ or larger, values for the total impedance $(\mathrm{Z})$ must be taken in calculating the voltage drop. Therefore, the equation should be modified to:

$V_{d}=\frac{\left(\frac{\frac{m v}{A}}{m}\right)_{z} \times I_{b} \times L}{1000}$

III. Design Verification: Verification is the stage that is most commonly associated with actual project achievement. The ICSFC is also designed to verify the system is working flawlessly. In particular, the chosen protective device, the time/current characteristics of the protective device and the ability of the earthing design system to stand up against the fault current must all work coherently. The design verification confirms that the outcome as designed is the same as the output as projected. The following 5 steps of the flow chart are:

Step six: Calculate R1 and R2. R1 is defined as the cable live resistance from the origin to the point of calculation. R2 is expressed as the CPC from the origin to the point of calculation. This concept is practically applied for cables less than $25 \mathrm{~mm} 2$. Cables larger than $25 \mathrm{~mm} 2$, the reactive component with the power factor must be involved in the calculation [21]. The values of $(\mathrm{R} 1+\mathrm{R} 2)$ per metre at a measured temperature of 20oC are given in table I1 [21] for different cable combinations up to $35 \mathrm{~mm} 2$ cross sectional area [8]. Due to the fact that these tables are based on $20 \mathrm{oC}$, two correction factors must be added to the value of $(\mathrm{R} 1+\mathrm{R} 2)$. These are the ambient temperature multiplier and the maximum operation temperature multiplier. Values are available in Table I2 and I3 respectively [22].

Step Seven: To comply with section 411.3 [21], the earth fault loop impedance Zs must be less than the maximum protective device impedance Zsmax so that any current that happens during a fault period is sufficiently enough to trip the protective device out within its maximum disconnection time. This achieves through a combination of characteristics that must work together, e.g. providing the main earthing protection CPC, an appropriate insulation of live parts, protective equipotential bonding for gas or water pipes and, finally, by adding an automatic disconnection protective device that must be able to meet its maximum disconnection time.

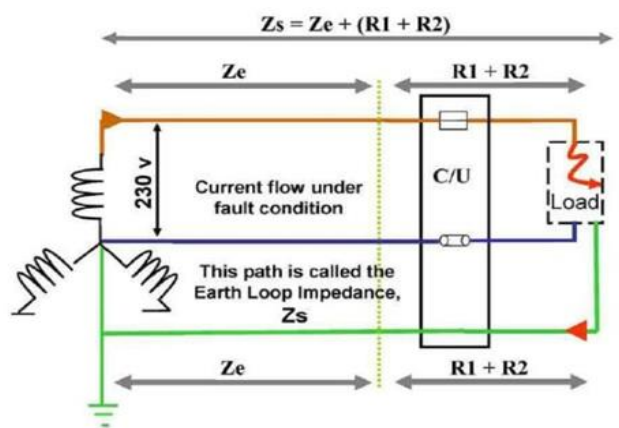

Figure 3: Earth fault loop impedance.

The value of $\mathrm{Z}_{\mathrm{e}}$ is obtained by either measuring the earth loop impedance at the origin of the installation or using figures provided by the DNO:

Table 5: Typical Ze Values given by electrical distributor [22]

\begin{tabular}{|l|c|}
\hline TN-C-S (PME) Supplies & $0.35 \Omega$ \\
\hline TN-S Supplies & $0.8 \Omega$ \\
\hline TT Supplies & $21 \Omega$ \\
\hline
\end{tabular}

Step Eight \& Nine: At these stages, it is worth checking the chosen protective device can withstand the fault current. It is also recommended to consider the overload current calculation too. The overload can exist for long periods of time. This current flows in the circuit conductors - not the CPC - and hence they must be able to withstand for long periods before the protective device eventually operates [18]. The co-ordination between the protective device and cable`s current currying capacity is shown below:

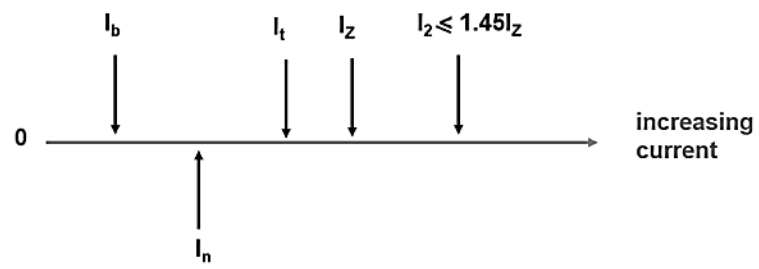

Figure 4: Co-ordination between Protective Device and conductor for overload current.

Where: $I_{2}$ is the current causing effective operation of the protective device.

This condition is proposed to safeguard operation of the chosen protective device within a time suitable to protect the conductor`s insulation against excessive increasing the cable temperature caused by the overload current [6, 21 and 22]. Based on section 434 [21] checking for protection against Fault Current (FC), this can be a huge current and must be broken within milliseconds before the conductor or insulation is damaged.

Published By:

Blue Eyes Intelligence Engineering

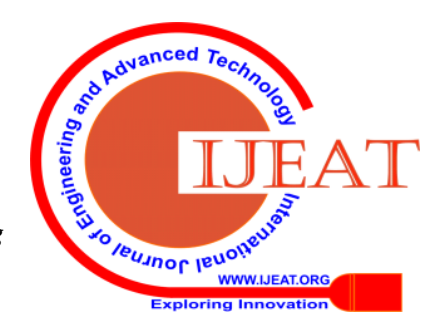


Depending on the nature of fault, this current can flow in the phase conductors or a phase conductor and CPC [1].

- $\quad$ Calculate / measure the prospective fault current $\mathrm{I}_{\mathrm{F}}$ : $I_{f}=\frac{U_{o} \times C_{\min }}{Z_{\text {s actual }}}$; Where $\mathrm{C}_{\min }$ is a voltage factor for minimum fault currents [20].

Calculate the cable withstand time for the fault current $\left(\mathrm{t}_{1}\right)$. This can be found from the 'adiabatic equation':

$$
t_{1}=\left(\frac{K \times S}{I_{f}}\right)^{2}
$$

Where: $\mathrm{t} 1$ is the maximum time in seconds that the fault current can safely flow.

$\mathrm{K}$ is a factor of the resistivity, temperature and heat capacity, tables 43.1 and 54.3 [21].

$\mathrm{S}$ is the CSA of the conductor (CPC) in $\mathrm{mm} 2$.

- Calculate the protective device disconnect time for the fault current $\left(\mathrm{t}_{2}\right)$. Appendix 3 provides operating curves for various protective devices where the disconnection time can be found easily [20].

- $\quad$ Check that $t_{1}>t_{2}$, the protective device will operate at $t_{2}$ seconds. The conductor can withstand the fault current for $t_{1}$ seconds. Therefore, the system will be safeguarded by the protective device against the calculated fault current as required by section 4332-1 [21].

Step Ten: Due to the fact that the CPC affords a passage to earth for short-circuit and fault currents to protect human/livestock and buildings as well as equipment. Therefore, it requires protective device operating times. The CPC also provides a fixed reference voltage ( 0 Volt). The 'adiabatic equation' is commonly used for determining the minimum CPC size, [21]:

$S=\frac{\sqrt{I_{f}^{2} t_{2}}}{K}$

The calculated $S$ should be equal to or less than chosen R2 from table I1 [22]. However, chapter 54 [21] allows a simple 'rule-of-thumb' method for determining the minimum CPC size. The chapter divides the system into three categories according to the line conductor`s cable size:

- If $\mathrm{S} \leq 16 \mathrm{~mm}^{2} \rightarrow \mathrm{CPC}$ size is the same when have chosen from the same material; otherwise $K_{1} / K_{2}$ $\times \mathrm{S}$.

- If $16 \leq \mathrm{S} \leq 35 \mathrm{~mm}^{2} \rightarrow \mathrm{CPC}$ size $=16$ when have chosen from the same material; otherwise $K_{1} / K_{2}$ $\times 16$.

- If $\mathrm{S}>35 \mathrm{~mm}^{2} \rightarrow$ CPC size $=\mathrm{S} / 2$ when have chosen from the same material; otherwise $K_{1} / K_{2}$ $\times \mathrm{S} / 2$.

\section{RESULTS}

The Instructive Cable Sizing Flow Chart (ICSFC) is attached in Appendix A.

\section{CONCLUSIONS}

The establishment of wiring installation is mainly depending upon the type of building and its use. In premises, part of the installation will be required to meet the needs of the various loads/areas of that building. It is also possible that in larger buildings several different voltages may be employed. Therefore, this attribute must be studied when choosing the wiring system to be employed.

The BS7671 states the regulations in a general format related to the specific wiring systems and their erection. These are all covered in Part 5. The ICSFC attached in appendix A in this paper is an instructive summary for selecting the correct cable size for the different types of installation. In addition, the flow chart is designed to comply entirely with the regulations of the BS 7671. It contains 10 consecutive arrangements. The first 5 steps to confirm the accurate management of the design and cable size selection with a suitable voltage drop. The last 5 steps come up with further inspection on the selection of the cable size and the protection system for the establishment. Each step was completely clarified with the help of equations and tables to allow for solid decisions making. This flow chart eradicates the need to remember any complicated equations. It will completely work through a calculation as stated in Appendix 4 of BS7671 IET regulations. The ICSFC is providing the users with tables`numbers and references for their design. This chart design is suitable for electrical installation designers as well as learners.

\section{REFERENCES}

1. BS EN 60909-0, "Short-circuit currents in three-phase a.c. systems. Calculation of currents, 2016.

2. C.R. Bayliss and B.J. Hardy, Transmission and distribution Electrical Engineering, 4th Edition, 2011.

3. Copper Association Development, "Earthing Practice", CDA Publication 119, February 1997.

4. Craig B. Smith Kelly Parameter, Energy Management Principles, 2nd Edition, November 2015.

5. F. de Leon, "Major factors affecting cable ampacity," Power Engineering Society General Meeting, 2006. IEEE, Montreal, Que.

6. Health and Safety Executive, Electricity at Work Regulations 1989, https://www.hse.gov.uk/pUbns/priced/hsr25.pdf

7. Health and Safety Executive, Safety in Electrical Testing At Work, INDG354, 23 Oct 2013.

8. IEC 60364-5-52, (2009), "Electrical installations in buildings - Part 552: Selection and erection of electrical equipment - Wiring systems", is the IEC standard governing cable sizing.

9. International Electrotechincal Commission, Electrical Installations Guide, 2016, http://lrf.fe.uni-lj.si/e_eir/SEGuide2016.pdf

10. International Electrotechincal Commission, IEC 60439, 4th edition, November 2004.

11. International Electrotechincal Commission, Uninterruptible power systems (UPS) - Part 2: Electromagnetic compatibility (EMC) requirements, IEC 62040-2:2016, November 2016.

12. Ioannis Konstantelos, Mingyang Sun, Goran Strbac, Quantifying demand diversity of households, Low Carbon London Learning Lab, September 2014.

13. James Stallcup, "Designing Electrical Systems”, Builder's Book, Inc, volume 2,May 2017.

14. M. Pratap Nair and K. Nithiyananthan, An Effective Cable Sizing Procedure Model for Industries and Commerial Buildings, International Journal of Electrical and Computer Engineering (IJECE), Vol. 6, No. 1, February 2016.

15. M. Zima, "Contributions to Security of Electric Power Systems", ETH, 2006.

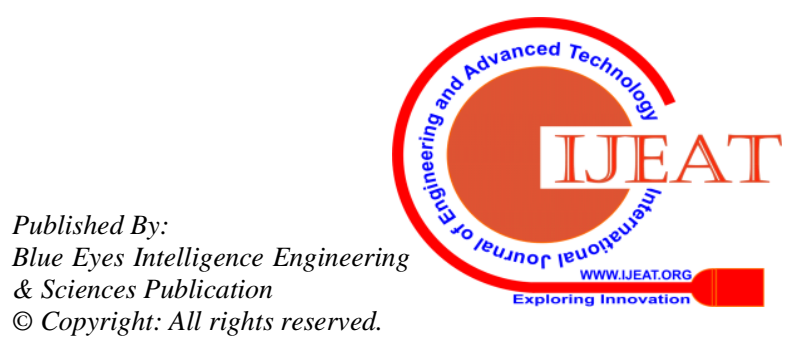


16. Nithiyananthan.K, Elavenil V, "CYMGRD Based Effective Earthing Design Model for Substation", 2011. International Journal for Computer Applications in Engineering Sciences Asia, Vol. I, No 3, pp. 341-346.

17. Obinna E. Igwe, "Cable Sizing and Its Effect on Thermal and Ampacity Values in Underground Power Distribution", 2016. University of Kentucky.

18. R. E. Henry, "Cable sizing for fast transient loads," Industrial and Commercial Power Systems, 2003. 2003 IEEE Technical Conference.

19. Telent,Report: E007146-001, DNO - SMART GRID COMMUNICATIONS REQUIREMENTS, Energy Network Association, $20^{\text {th }}$ Dec. 2011.

https://www.energynetworks.org/assets/files/electricity/engineering/te lecoms/eitc/restricted/Reference\%20Doc/Telent.pdf

20. The Electricity Safety, Quality and Continuity Regulations, 2002, http://www.legislation.gov.uk/uksi/2002/2665/pdfs/uksi 20022665_e n.pdf.

21. The institution of Engineering and Technology and BSI, Requirements for Electrical Installations, IET Wiring Regulations Eighteenth Edition, 2018.

22. The institution of Engineering and Technology IET, On-Site Guide BS7671:2018.

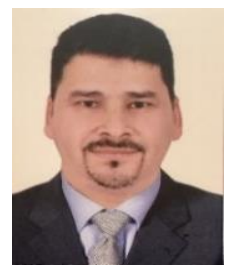

\section{AUTHOR PROFILE}

Dr. Emad Al-Mahdawi has a PhD in Electrical Power Engineering from state Polytechnic university of Saint Petersburg. He has also studied in university of Kent at Social Science Department for getting the Postgraduate Certificate in Higher Education in 2018. The author also completed Diploma in Teaching in FE in 2013. He focuses his researches on the field of Electrical Power Engineering as well as International and National Higher Education. To develop solutions to electrical engineering problems using new and existing technology, the author has held Chartered Engineering from the Institution of Engineering and Technology of the United Kingdom. The author also is a Fellowship of Higher Education Academy. He is presently a lecturer at Midkent College, UK. He has also got a qualified higher education teaching status from University of Cranfield.

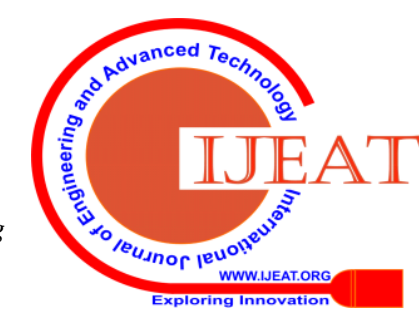


An Instructive Flow Chart for Optimising the Electrical Cable Sizing Design Procedure

Appendix A: Instructive Cable Sizing Flow Chart (ICSFC) Complaint with BS7671.

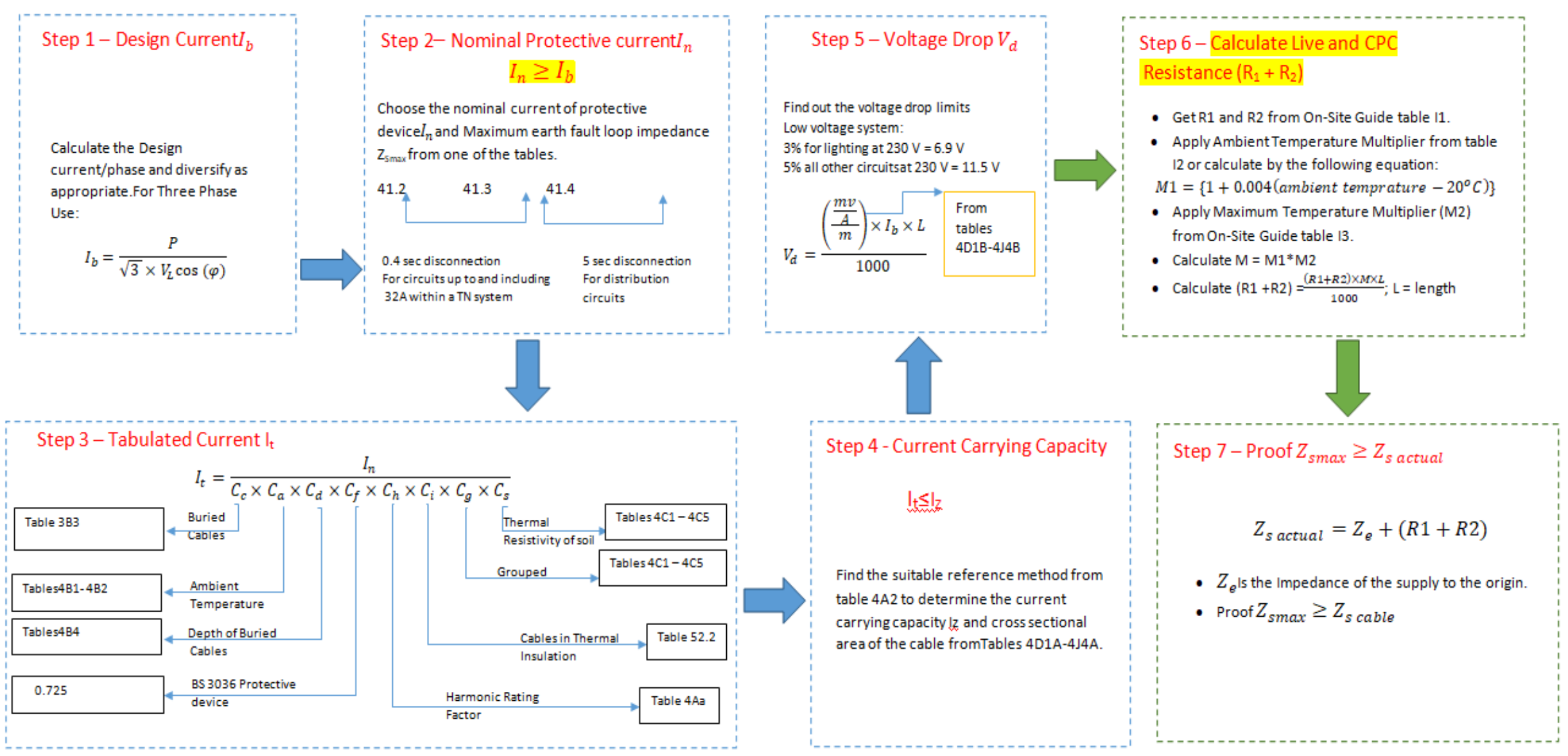

Step $10-$ Check for the right chosen CPC

$$
S=\frac{\sqrt{I_{f}^{2} \times t}}{K}
$$

$\mathrm{K}=$ factor of resistivity, temperature, heat capacity and conductor materialfor the protective conductor. Tables 54.2 to 54.6

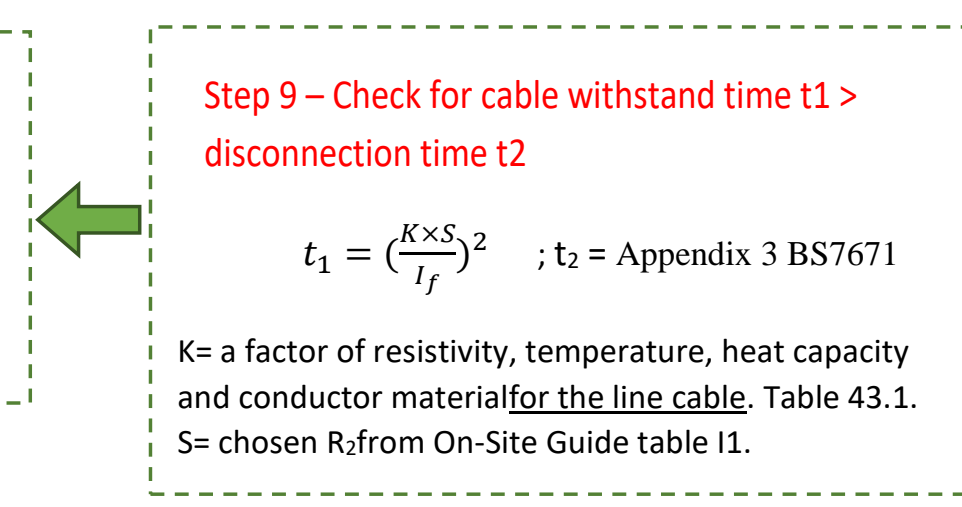

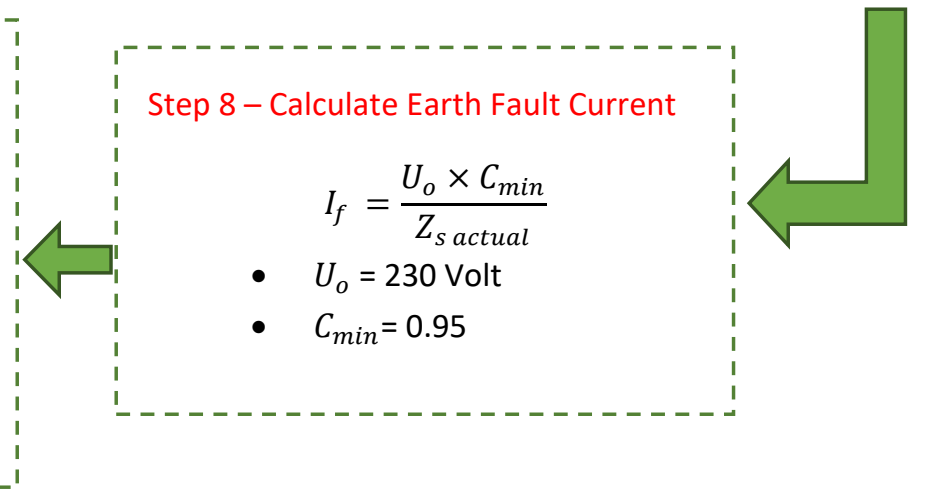

Retrieval Number: D6676049420/2020@BEIESP DOI: 10.35940/ijeat.D6676.049420 Journal Website: www.ijeat.org
Published By:

Blue Eyes Intelligence Engineering

\& Sciences Publication 